\title{
POLÍTICAS PÚBLICAS EDUCACIONAIS CONTRADITÓRIAS: A ALFABETIZAÇÃO EM FOCO
}

\author{
POLÍTICAS PÚBLICAS EDUCATIVAS CONTRADICTORIAS: LA ALFABETIZACIÓN \\ EN FOCO
}

CONTRADITORY EDUCATIONAL PUBLIC POLICIES: THE LITERACY IN FOCUS

\author{
Sergio Brasil FERNANDES ${ }^{1}$ \\ Ronaldo Bernardino COLVERO ${ }^{2}$
}

RESUMO: Neste artigo, abordam-se contradições entre as políticas públicas que abrangem a alfabetização, particularmente entre o Plano Nacional de Educação - PNE e a Base Nacional Comum Curricular - BNCC. Ressalta-se a importância da alfabetização como suporte para que o cidadão possa desenvolver-se plenamente, exerça a cidadania e qualifique-se para o trabalho. Evidencia-se que o PNE estabelece que a alfabetização das crianças deve ocorrer até o final do $3^{\circ}$ (terceiro) ano do Ensino Fundamental - EF, enquanto a BNCC determina que os alunos devem estar alfabetizados até o $2^{\circ}$ (segundo) ano do EF. Essa desconexão demonstra um conflito entre normas jurídicas que são hierarquicamente diferentes, porque o PNE trata-se de uma Lei, enquanto a BNCC é uma Resolução. Por fim, enfatiza-se que a alfabetização se mantém como um dos graves problemas da educação brasileira e que sua resolução passa, em grande parte, pelo trabalho efetivo da comunidade escolar (equipes diretivas, professores, alunos, pais e mães, etc.) nos educandários.

PALAVRAS-CHAVE: Alfabetização. Educação. Políticas públicas.

RESUMEN: En este artículo, se abordan contradicciones entre las políticas públicas que abarcan la alfabetización, particularmente entre el Plan Nacional de Educación - PNE y la Base Nacional Común Curricular - BNCC. Se resalta la importancia de la alfabetización como soporte para que el ciudadano pueda desarrollarse plenamente, ejercer la ciudadanía y calificarse para el trabajo. Se evidencia que el PNE establece que la alfabetización de los niños debe ocurrir hasta el final del $3^{\circ}$ (tercer) grado de la Educación Primaria Basica - EF, mientras que la BNCC determina que los alumnos deben estar alfabetizados hasta el $2^{\circ}$ (segundo) grado de la Primaria. Esta desconexión demuestra un conflicto entre normas jurídicas que son jerárquicamente diferentes, porque el PNE se trata de una Ley, mientras que la BNCC es una Resolución. Por último, se enfatiza que la alfabetización se mantiene como uno de los graves problemas de la educación brasileña y que su resolución pasa, en gran parte, por el trabajo

\footnotetext{
${ }^{1}$ Universidade Federal do Pampa (UNIPAMPA), São Borja - RS - Brasil. Aluno do Programa de Pós-Graduação em Políticas Públicas - PPGPP (mestrado profissional). ORCID: <https://orcid.org/0000-0003-2614-6414>. Email: sergiohaiti33@hotmail.com

${ }^{2}$ Universidade Federal do Pampa (UNIPAMPA), São Borja - RS - Brasil. Professor do Programa de PósGraduação em Políticas Públicas - PPGPP (mestrado profissional). ORCID: <https://orcid.org/0000-0003-29588656>.E-mail: ronaldocolvero@unipampa.edu.br
} 
efectivo de la comunidad escolar (equipos directivos, profesores, alumnos, padres y madres, etc.) en las escuelas.

PALABRAS CLAVE: Alfabetización. Educación. Políticas públicas.

ABSTRACT: In this article, contradictions between public policies that cover literacy, particularly between the National Education Plan-PNE and the National Curricular Common Base -BNCC are address. It is emphasizing the importance of the literacy as a support so that the citizen can fully develop, exercise citizenship and qualify for work. It is evident that the PNE establishes that the children's literacy must occur by the end of the 3rd year of Elementary School-EF, while the BNCC determines that students must be literate by the 2 nd year of the EF. This disconnection demonstrates a conflict between legal norms that are hierarchically different, because the PNE is a Law, while the BNCC is a Resolution. Finally, it is emphasized that literacy continues as one of the serious problems of Brazilian education and that its resolution passes, in large part, by the effective work of the school community (management teams, teachers, students, fathers and mothers, etc.) in the schools.

KEYWORDS: Literacy. Education. Public policy.

\section{Introdução}

No Brasil, a alfabetização - inserida no grande escopo de um dos bens sociais mais caros em uma sociedade moderna que é a educação - tem sido tema recorrente nos planos de governos e constantemente presente na agenda de políticas públicas, uma vez que há várias décadas não se consegue alfabetizar todas as crianças, apesar de estar universalizado o acesso ao ensino fundamental - EF, particularmente às séries iniciais.

Estudos como os de Frangella (2016) e Perovano e Costa (2017) mostram que, apesar da implementação de diversas políticas públicas educacionais voltadas à alfabetização e do aparente esforço estatal para efetivá-las com êxito, os resultados demonstram evolução pouco satisfatória, muito por conta de articulações inadequadas e/ou contraditórias dessas políticas.

Especificamente, quanto à alfabetização das crianças, considerando a relevância desse processo, o Estado 3 inseriu no Plano Nacional de Educação - $\mathrm{PNE}^{4}$ uma meta voltada à alfabetização, qual seja: "Meta 5: alfabetizar todas as crianças, no máximo, até o final do $3^{\circ}$ (terceiro) ano do ensino fundamental." (BRASIL, 2014, p. 3).

${ }^{3}$ Uma forma de organização social que se utiliza de elementos coercitivos para regulamentar a vida em sociedade em um determinado território (WEBER, 2004).

${ }^{4}$ Política pública de Estado, voltada à educação no Brasil, que estabelece metas a serem atingidas durante a década 2014-2024. 
Como uma estratégia que visa contribuir para que essa meta seja atingida, firmou-se o Pacto Nacional pela Alfabetização na Idade Certa - PNAIC $^{5}$ que, segundo o Ministério da Educação - MEC, “[...] é um compromisso formal assumido pelos governos federal, do Distrito Federal, dos estados e municípios de assegurar que todas as crianças estejam alfabetizadas até os oito anos de idade, ao final do $3^{\circ}$ ano do ensino fundamental." (BRASIL, 2017c).

Observa-se que há coerência entre o que estabelecem o PNE e o PNAIC, no que se refere à alfabetização. Isso é o que, naturalmente, se espera de uma política que surge como estratégia - o PNAIC - para atingir uma meta estabelecida por outra política maior - o PNE.

No entanto, por imposição do PNE, a Base Nacional Comum Curricular - BNCC $^{6}$ aprovada pelo Conselho Nacional de Educação - CNE foi implementada pelo MEC, trazendo algumas mudanças que foram consideradas polêmicas, entre outras: a alfabetização até o segundo ano do ensino fundamental - EF.

Nesse contexto de alterações nos rumos da educação, ressalta-se que a BNCC definiu que a alfabetização deve ocorrer até o segundo ano do EF, estando, portanto, em desacordo com o que prevê o PNE. Além disso, desconsidera o que especialistas nas áreas da linguística, da neuropediatria, da pedagogia e da psicopedagogia afirmam em relação à idade ideal ou adequada para inserir as crianças em um contexto de alfabetização, isto é, a partir dos seis anos de idade. Isso sugere que pode ser um tempo muito curto entre o inserir a criança em um contexto de alfabetização (a partir dos seis anos) e ela se tornar alfabetizada (aos sete anos), uma vez que cada criança desenvolve sua aprendizagem de forma individualizada.

Essa realidade contestável e polêmica, apesar de "espinhosa", é a que se pretende abordar neste artigo. Para tanto, a partir desta introdução, entende-se que há necessidade de ressaltar a importância da alfabetização, bem como as políticas públicas que a envolvem, particularmente as que se mostram contraditórias, e, por fim, de apresentar as considerações finais deste artigo.

\section{A importância da alfabetização}

Conviver em uma sociedade exige uma série de fatores a serem atendidos e grande parte deles passa pela ação do Estado. Há um rol imenso de aspectos necessários para esse convívio

${ }^{5}$ Política pública de governo instituída pela Portaria $n^{\circ} 867$, de 4 de julho de 2012, que, com a alternância de governo, foi revogada pela Portaria $\mathrm{n}^{\circ} 826$, de 7 de julho de 2017, mas manteve a ideia central de alfabetizar as crianças até o $3^{\circ}$ ano do ensino fundamental.

${ }^{6}$ A BNCC foi aprovada pelo CNE, por meio da Resolução CNE/CP no 2, de 22 de dezembro de 2017. 
social aconteça de um modo organizado e salutar. Dentre tais necessidades estão os bens sociais dos quais se ressalta a educação que é um direito social previsto no Art. $6^{\circ}$ da $\mathrm{CF} / 1988$ (BRASIL, 2016). Ademais, cabe enfatizar que o Art. 205 da CF/1988 prevê que: "A educação, direito de todos e dever do Estado e da família, será promovida e incentivada com a colaboração da sociedade, visando ao pleno desenvolvimento da pessoa, seu preparo para o exercício da cidadania e sua qualificação para o trabalho." (Idem, p. 123).

Entende-se que para se efetivar o que estabelece o Art. 205 da CF/1988 a alfabetização deve ser priorizada. Outrossim, impõem-se a assertiva de que para que o cidadão obtenha direitos básicos garantidos pela Constituição - entre eles a educação - e, a partir dela, pleno desenvolvimento, preparo para exercer a cidadania e qualificação para o trabalho a alfabetização é um fator preponderante e essencial. Portanto, para o país a alfabetização deve ser tratada como uma das metas mais importantes a serem alcançadas.

Dada essa importância considerada, faz-se necessário determinar um parâmetro conceitual para a alfabetização. Assim sendo, vale enfatizar que o conceito de alfabetização se constrói de maneira dinâmica ao longo dos anos, considerando distintas didáticas e seus diversos métodos e técnicas de ensino, também heterogêneos, além de abordagens teóricas as mais variadas.

De acordo com os Parâmetros Curriculares Nacionais - PCNs: língua portuguesa,

[...] a alfabetização não é um processo baseado em perceber e memorizar, e, para aprender a ler e a escrever, o aluno precisa construir um conhecimento de natureza conceitual: ele precisa compreender não só o que a escrita representa, mas também de que forma ela representa graficamente a linguagem. (BRASIL, 1997, p. 20).

Nessa ideia conceitual de alfabetização adotada no Brasil, via PCNs, pode-se verificar a perspectiva construtivista. Avanços ou retrocessos conceituais podem variar, conforme a tendência teórica, o que pode influenciar, positiva ou negativamente, o processo de alfabetização.

Assim, vinte anos depois, a BNCC apresenta o seguinte conceito: “[...] alfabetizar é trabalhar com a apropriação pelo aluno da ortografia do português do Brasil escrito, compreendendo como se dá este processo (longo) de construção de um conjunto de conhecimentos sobre o funcionamento fonológico da língua pelo estudante.” (BRASIL, 2017a, p. 88). Essa conceituação explicita o viés dos defensores do método fônico, renegando o construtivismo. 
Por isso e em virtude de ir além do estrito conhecimento ortográfico e fonológico proposto pela BNCC, vale citar a conceituação apresentada por Costa e Putkul (2018, p. 235):

[...] a alfabetização é o processo que possibilita as crianças, jovens e adultos a relacionar-se com o mundo também por meio dos textos escritos que veiculam relações de interlocução, ou seja, apresentam posicionamentos, discordâncias, concordâncias e objeções sobre os mais variados temas que povoam as relações humanas.

Diante dessas ideias conceituais, propõe-se que a alfabetização - independentemente da perspectiva teórico-metodológica - seja um processo transformador, no sentido de tornar o ser humano leitor e escritor, isto é, que todos saibam ler e escrever, estabelecendo uma comunicação efetiva.

Tal proposta ancora-se na experiência de Snow (2017) que afirma que há evidências que os métodos globais - parecem um pouco com o construtivismo brasileiro - apresentam bons resultados na pré-escola, enquanto que o ensino específico das relações entre sons e letras traz melhores resultados no $1^{\circ}$ ano. Sendo assim, a autora defende a união dos especialistas e que as redes de ensino assumam uma postura conciliatória, porque o emprego da linguagem é importante durante toda a escolarização, mas ressalta que a aprendizagem das relações entre sons e letras pode ser primordial para os alunos no $1^{\mathrm{o}}$ ano do EF.

Então, como deve ocorrer a alfabetização? Entende-se que podem/devem haver várias formas de alfabetizar, ressaltando que todas elas devem respeitar o tempo individual da criança. Snow (2017), por sua vez, defende a conciliação entre os especialistas, similar à promovida nos Estados Unidos, por meio da Academia Nacional Americana de Ciência, no sentido de promover uma linguagem rica durante toda a escolarização, mas destinar um período de ensino, especialmente, no $1^{\circ}$ ano sobre as relações entre sons e letras. Segundo a autora, isso não faria nenhum mal aos alunos, podendo ser essencial para alguns deles. Em síntese, seria um mix de construtivismo e de método fônico, particularmente, no início da alfabetização.

A partir dessa proposição, destaca-se a argumentação de Soares (2004, p. 14):

Dissociar alfabetização e letramento é um equívoco porque, no quadro das atuais concepções psicológicas, linguísticas e psicolinguísticas de leitura e escrita, a entrada da criança (e também do adulto analfabeto) no mundo da escrita ocorre simultaneamente por esses dois processos: pela aquisição do sistema convencional de escrita - a alfabetização - e pelo desenvolvimento de habilidades de uso desse sistema em atividades de leitura e escrita, nas práticas sociais que envolvem a língua escrita - o letramento. Não são processos independentes, mas interdependentes, e indissociáveis: a alfabetização desenvolve-se no contexto de e por meio de práticas sociais de leitura e de escrita, isto é, através de atividades de letramento, e este, por sua 
vez, só se pode desenvolver no contexto da e por meio da aprendizagem das relações fonema-grafema, isto é, em dependência da alfabetização. (grifos da autora).

E, quando deve ocorrer a alfabetização? A alfabetização pode ocorrer em diversas fases da vida, inclusive na fase adulta ou na terceira idade, por exemplo. Quanto à realidade que se pretende como ideal, de acordo com o PNE, tem-se a idade de 8 anos. No entanto, é preciso considerar que a aprendizagem pode variar de criança para criança. Sobre esse aspecto, segundo Muniz e Muniz (2016), é preciso (re)pensar a alfabetização na idade certa, porque mais importante que se adequar as imposições legais e fazer com que o processo de alfabetização das crianças seja enriquecedor e prazeroso, tanto para os alunos quanto para os professores.

Das respostas a esses questionamentos constata-se que "como e, principalmente, quando alfabetizar" são pontos nevrálgicos das políticas públicas que tratam da alfabetização, pois se verificam contradições nas palavras e nas ideias, ou "antíteses e paradoxos" como prefere dizer Frangella (2016), que interferem na pedagogia a ser utilizada nas aulas das séries iniciais, particularmente nos três primeiros anos do EF. São essas contradições que precisam ser abordadas e, por meio de ações políticas adequadas, devidamente corrigidas para que hajam rumos definidos e seguidos com persistência, sem mudanças constantes dos caminhos que levam a atingir determinada meta - neste caso, a meta 5 do PNE.

\section{Políticas públicas que envolvem a alfabetização no Brasil}

A alfabetização mantém-se na agenda de políticas públicas educacionais, como uma demanda da sociedade, porque é um problema que persiste há décadas e, desse modo, não se deve descontinuar as políticas que a envolvem. Apesar disso, verifica-se que, por vezes, a falta de cultura de desenvolver políticas de Estado faz com que governos deflagrem a descontinuidade de algumas políticas ou a substituição por outras com o intuito de promover governos, no sentido de propagar a ideia de idealizadores de um determinado programa/plano.

Observa-se que a implementação de políticas educacionais (Quadro 1) cujo alvo é, direta ou indiretamente, a alfabetização tem sido recorrente, particularmente nas três últimas décadas. No entanto, a efetividade dessas políticas públicas pode ser questionada, uma vez que não têm apresentado os resultados pretendidos. 
Quadro 1: Correlação entre normas jurídicas e objetivos inerentes à alfabetização

\begin{tabular}{|c|c|}
\hline Normas Jurídicas / Políticas Públicas & Objetivos inerentes à alfabetização \\
\hline $\begin{array}{l}\text { Constituição da República Federativa do Brasil } \\
\text { (1988) }\end{array}$ & - erradicar o analfabetismo (Art. 214). \\
\hline $\begin{array}{l}\text { Lei de Diretrizes e Bases da Educação Nacional - } \\
\text { LDB (1996) }\end{array}$ & - \\
\hline $\begin{array}{l}\text { Parâmetros Curriculares Nacionais: língua portuguesa } \\
\text { (1997-2017) }\end{array}$ & $\begin{array}{l}\text { - A alfabetização, considerada em seu sentido restrito } \\
\text { de aquisição da escrita alfabética, ocorre dentro de um } \\
\text { processo mais amplo de aprendizagem da Língua } \\
\text { Portuguesa. (BRASIL, } 1997, \text { p. } 28 \text { ). }\end{array}$ \\
\hline $\begin{array}{l}\text { Parâmetros em Ação: Alfabetização } \\
\text { (1999) }\end{array}$ & - formação continuada de professores alfabetizadores \\
\hline $\begin{array}{l}\text { Documento Alfabetizar com textos } \\
\text { (1999) }\end{array}$ & - formação continuada de professores alfabetizadores. \\
\hline $\begin{array}{l}\text { Plano Nacional de Educação I (2001-2010) } \\
\text { Lei n⿳0 } 10.172 \text {, de } 9 \text { de janeiro de } 2001 .\end{array}$ & $\begin{array}{l}\text { - alfabetizar } 10 \text { milhões de jovens e adultos, em cinco } \\
\text { anos [até 2006] e, até o final da década [2011], } \\
\text { erradicar o analfabetismo. }\end{array}$ \\
\hline $\begin{array}{l}\text { Programa de Formação de Professores } \\
\text { Alfabetizadores - PROFA (2001-2003) }\end{array}$ & - formação continuada de professores alfabetizadores. \\
\hline $\begin{array}{l}\text { Pró-letramento } \\
(2006-2012)\end{array}$ & - formação continuada de professores alfabetizadores. \\
\hline $\begin{array}{l}\text { Plano de Metas Compromisso Todos pela Educação } \\
\text { Decreto } n^{\circ} 6.094 \text {, de } 24 \text { de abril de } 2007\end{array}$ & $\begin{array}{l}\text { - alfabetizar as crianças até, no máximo, os oito anos } \\
\text { de idade. (Inciso II, do Art. } 2^{\circ} \text { ). }\end{array}$ \\
\hline $\begin{array}{l}\text { Programa de Desenvolvimento da Educação - PDE } \\
(2007)\end{array}$ & $\begin{array}{l}\text { - alfabetizar as crianças até, no máximo, os oito anos } \\
\text { de idade. }\end{array}$ \\
\hline $\begin{array}{l}\text { Programa Mais Educação (2007-2016) } \\
\text { Portaria } \text { n }^{\circ} 17 \text {, de } 24 \text { de abril de } 2007\end{array}$ & 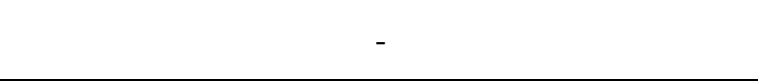 \\
\hline $\begin{array}{l}\text { Pacto Nacional para Alfabetização na Idade Certa - } \\
\text { PNAIC (2012-2017) } \\
\text { Portaria }{ }^{\circ} 867 \text {, de } 4 \text { de julho de 2012. (revogada) }\end{array}$ & $\begin{array}{l}\text { - alfabetizar as crianças até, no máximo, os oito anos } \\
\text { de idade, ao final do } 3^{\circ} \text { ano do ensino fundamental. }\end{array}$ \\
\hline $\begin{array}{l}\text { Plano Nacional de Educação II - PNE (2014-2024) } \\
\text { Lei no } 13.005 \text {, de } 25 \text { de junho de } 2014\end{array}$ & $\begin{array}{l}\text { - alfabetizar todas as crianças até o } 3^{\circ} \text { ano do EF. } \\
\text { - erradicar o analfabetismo até o fim de } 2024 .\end{array}$ \\
\hline $\begin{array}{l}\text { Programa Novo Mais Educação (2016-atual) } \\
\text { Portaria } n^{\circ} 1.144, \text { de } 10 \text { de outubro de } 2016\end{array}$ & $\begin{array}{l}\text { - contribuir para a alfabetização das crianças por meio } \\
\text { de acompanhamento pedagógico específico. }\end{array}$ \\
\hline $\begin{array}{l}\text { Pacto Nacional para Alfabetização na Idade Certa } \\
\text { - PNAIC (2017-atual) } \\
\text { Portaria n }{ }^{\circ} 826 \text {, de } 7 \text { de julho de } 2017\end{array}$ & $\begin{array}{l}\text { - garantir que todos os estudantes dos sistemas } \\
\text { públicos de ensino estejam alfabetizados, em Língua } \\
\text { Portuguesa e em Matemática, até o final do } 3^{\circ} \text { ano do } \\
\text { ensino fundamental (Art. } 5^{\circ} \text { ). }\end{array}$ \\
\hline $\begin{array}{l}\text { Base Nacional Comum Curricular - BNCC } \\
\text { Resolução CNE/CP n }{ }^{\circ} \text { 2, de } 22 \text { de dezembro de } 2017\end{array}$ & $\begin{array}{l}\text { - a alfabetização deve ser o foco da ação pedagógica } \\
\text { nos dois primeiros anos do EF. }\end{array}$ \\
\hline $\begin{array}{l}\text { Programa Mais Alfabetização } \\
\text { Portaria } n^{\circ} 142 \text {, de } 22 \text { de fevereiro de } 2018\end{array}$ & $\begin{array}{l}\text { - contribuir para a alfabetização (leitura, escrita e } \\
\text { matemática) dos estudantes regularmente } \\
\text { matriculados no } 1^{\circ} \text { ano e no } 2^{\circ} \text { ano do ensino } \\
\text { fundamental [...]. }\end{array}$ \\
\hline
\end{tabular}

Fonte: os autores

Nesse amplo contexto de legislações, a fim de manter o foco principal deste artigo, isto é, a alfabetização das crianças, destaca-se a discrepância que há entre o que prescreve a meta 5 do PNE e o que estabelece a BNCC no que se refere à alfabetização, especificamente quanto à fase em que se deve construir e consolidar esse processo. Por isso, enfatiza-se a análise dessas duas políticas públicas, além do PNAIC como estratégia contributiva para atingir a meta 5 do PNE e o Programa Mais Alfabetização, resultante da BNCC. 


\section{Alfabetização: PNE versus BNCC}

Primeiramente, vale salientar que o PNE estabelece, em seu Art. $2^{\circ}$, como primeira diretriz, a erradicação do analfabetismo e isso, inevitavelmente, passa pela alfabetização ${ }^{7}$. Sendo assim, a partir dessa diretriz, dentre outras metas, projetou-se a meta 5 do PNE que visa a alfabetização das crianças até o término do $3^{\circ}$ ano do EF.

Outrossim, o PNE aponta, por meio da estratégia 7.1), a necessidade de:

[...] estabelecer e implantar, mediante pactuação interfederativa, diretrizes pedagógicas para a educação básica e a base nacional comum dos currículos, com direitos e objetivos de aprendizagem e desenvolvimento dos (as) alunos (as) para cada ano do ensino fundamental e médio, respeitada a diversidade regional, estadual e local; (BRASIL, 2014, p. 4).

Visando implementar essa estratégia, o MEC formulou uma proposta de uma nova BNCC que foi aprovada pelo CNE, cuja definição estabelece que:

A Base Nacional Comum Curricular (BNCC) é um documento de caráter normativo que define o conjunto orgânico e progressivo de aprendizagens essenciais que todos os alunos devem desenvolver ao longo das etapas e modalidades da Educação Básica, de modo a que tenham assegurados seus direitos de aprendizagem e desenvolvimento, em conformidade com o que preceitua o Plano Nacional de Educação (PNE). (BRASIL, 2017a, p. 7, grifo no original).

Nessa definição transcrita, explicita-se uma contradição, qual seja: “[...] em conformidade com o que preceitua o Plano Nacional de Educação (PNE)", pois não é isso que se verifica no que se refere à alfabetização. Enquanto o PNE estabelece que a alfabetização das crianças deve ocorrer até o final do $3^{\circ}$ (terceiro) ano do EF, a BNCC determina que:

Nos dois primeiros anos do Ensino Fundamental, a ação pedagógica deve ter como foco a alfabetização, a fim de garantir amplas oportunidades para que os alunos se apropriem do sistema de escrita alfabética de modo articulado ao desenvolvimento de outras habilidades de leitura e de escrita e ao seu envolvimento em práticas diversificadas de letramentos. (BRASIL, 2017, p. 57, grifo nosso).

$[\ldots]$

No Ensino Fundamental - Anos Iniciais, os componentes curriculares tematizam diversas práticas, considerando especialmente aquelas relativas às culturas infantis tradicionais e contemporâneas. Nesse conjunto de práticas, nos dois primeiros anos desse segmento, o processo de alfabetização deve ser o foco da ação pedagógica. (BRASIL, 2017, p. 61, grifo nosso).

$[\ldots]$

${ }^{7}$ Inclui-se a alfabetização de alunos especiais, a de jovens e adultos. 
Embora, desde que nasce e na Educação Infantil, a criança esteja cercada e participe de diferentes práticas letradas, é nos anos iniciais $\left(1^{\circ} \mathbf{e} 2^{\circ}\right.$ anos) do Ensino Fundamental que se espera que ela se alfabetize. Isso significa que a alfabetização deve ser o foco da ação pedagógica. (BRASIL, 2017a, p. 87, grifo nosso).

Verifica-se que há uma ordem expressa reiterada no texto da BNCC, enfatizando que as crianças com seis anos ( $1^{\circ}$ ano do $\left.\mathrm{EF}\right)$ e sete anos ( $2^{\circ}$ ano do $\left.\mathrm{EF}\right)$ serão alvos de ações pedagógicas voltadas, prioritariamente, para a alfabetização. Isso significa que, além de contrariar o que estabelece o PNE, a BNCC desconsidera a opinião abalizada de especialistas. Um grupo de cientistas das áreas de linguística, neurociências, psicolinguística e psicologia encaminhou uma nota em que analisa a BNCC, criticando fortemente a proposta de alfabetização (INSTITUTO ALFAEBETO, 2017). Vale salientar que “[...] o grupo é formado por pessoas com publicações em revistas científicas internacionais de alto prestígio, sendo que algumas delas também têm enorme experiência prática na área." (OLIVEIRA, 2017), o que lhe garante credibilidade para expor as deficiências da BNCC.

A questão é que a fixação de uma idade mínima para a alfabetização das crianças sem oferecer as condições básicas para o aprendizado ocorra é "mais do mesmo". Decretar que a alfabetização se dê até o $1^{\circ}$, o $2^{\circ}$ ou o $3^{\circ}$ ano não resolve o problema, apenas pressiona os envolvidos nesse processo, particularmente crianças, para atingir as metas estipuladas e responsabiliza professores quando essas metas não são atingidas.

Com base em estudo de Muniz e Muniz (2016), pode-se afirmar que as políticas educacionais tendem a exigir esforço das crianças na busca da alfabetização, mas especialmente para obterem bons desempenhos nas avaliações externas a que são submetidas (ANA, Provinha Brasil, etc.), além das provas cotidianas da própria escola. Na mesma senda, seguem os professores “[...] preocupados com os conteúdos a serem ministrados, muitas vezes acabam por suprimir o lúdico, apenas 'introduzindo' as matérias para dar conta do currículo.” (Idem, p. 29).

Mas, por que a BNCC contraria o PNE e desconsidera a opinião de especialistas? $\mathrm{Na}$ busca por uma resposta adequada a essa questão, vale enfatizar a argumentação de Oliveira (2017) sobre os obstáculos que o próprio país cria, dificultando o avanço na área da educação:

O que impede o Brasil de avançar na educação? O processo de encaminhamento da BNCC esclarece as razões disso: o Brasil quer ser diferente. Em qualquer país democrático e com sistemas educacionais razoáveis, a elaboração de programas de ensino segue um ritual. No país das jabuticabas, criamos um ritual próprio, fadado ao fracasso. [...] Audiências públicas e consultas via internet não substituem o debate e o confronto de ideias - essencial em um processo desta natureza. Deu no que deu. Sequer 
conseguimos fazer um programa de ensino decente para dizer o que precisa ser ensinado nas escolas. (Em: https://veja.abril.com.br/blog/educacao-emevidencia/alfabetizacao-na-bncc-mais-um-retrocesso-na-educacao/).

Sendo assim, as divergências entre a BNCC e o PNE, no que tange à alfabetização, também, podem ser consideradas como mais alguns obstáculos erguidos pelo próprio Brasil, contribuindo para a estagnação do país em termos educacionais.

Trilhando essa senda de apontar as dificuldades enfrentadas pela educação brasileira, a implementação da política pública Programa Mais Alfabetização pode ajudar a elucidar alguns aspectos que respondem ao questionamento proposto, pois a exemplo do que ocorre com a BNCC em relação ao PNE, o Mais Alfabetização também estabelece ideias contraditórias/desconexas em relação ao PNAIC.

\section{Mais desconexões entre as políticas públicas de alfabetização}

As alegações para as desconexões provocadas pela aprovação da BNCC em relação ao PNE não ficam claras no texto da Base. No entanto, tais motivações tornaram-se mais explicitas, a partir do início de 2018, com a adoção de mais uma política pública de governo, ajudando a entender alguns dos motivos dessas desconexões.

Na busca pela afirmação do que foi instituído pela BNCC em relação à alfabetização, eis que surge o Programa Mais Alfabetização, política pública criada pelo MEC, por meio da Portaria $\mathrm{n}^{\mathrm{o}}$ 142, de 22 de fevereiro de 2018, cujo objetivo exposto em seu Art. $1^{\circ}$ é “[...] fortalecer e apoiar as unidades escolares no processo de alfabetização, para fins de leitura, escrita e matemática, dos estudantes no $1^{\circ}$ ano e no $2^{\circ}$ ano do ensino fundamental." (BRASIL, 2018b, p. 54).

O texto da Portaria reforça, em vários trechos, a contradição entre o que prevê o PNE e a proposta da BNCC, no que se refere à alfabetização. Ressalta-se o seguinte:

CONSIDERANDO: [...] Que, conforme a Base Nacional Comum Curricular - BNCC (Resolução CNE/CP $n^{\circ}$ 2, de 22 de dezembro de 2017), nos dois primeiros anos do ensino fundamental, a ação pedagógica deve ter como foco a alfabetização, a fim de garantir amplas oportunidades, para que os alunos se apropriem do sistema de escrita alfabética, de modo articulado ao desenvolvimento de outras habilidades de leitura e de escrita e ao seu envolvimento em práticas diversificadas de letramentos [...] (BRASIL, 2018b, p. 54, grifo nosso).

Ora, se a BNCC tem como prazo para entrar em vigor o ano de 2020, porque o governo cria um programa (o Mais Alfabetização) dois anos antes de sua implementação? A resposta a 
essa questão pode estar atrelada às eleições (2018 é ano de eleição), afinal o programa "cria" 200.000 postos de trabalho o que poderia contribuir para a melhoria da imagem um governo com baixa taxa de popularidade em ano de eleição.

Ademais, essa estratégia ${ }^{8}$ adotada pelo MEC supõe o despreparo do Ministério em relação a suas próprias convicções ou confirma a falta delas, pois estabelece ações de execução fadadas ao insucesso: “Art. $4^{\circ}[\ldots] \S 1^{\circ} \mathrm{O}$ apoio técnico dar-se-á por meio de processos formativos, do auxílio do assistente de alfabetização às atividades estabelecidas e planejadas pelo professor alfabetizador [...]" (BRASIL, 2018b, p. 54). Afinal, não houve tempo adequado para que os professores revissem suas ações pedagógicas para uma eventual adequação a nova BNCC, o que por si só inviabiliza uma ação pedagógica concreta por parte dos assistentes, que deve ser orientada pelos professores alfabetizadores.

Expostos tais aspectos do Programa Mais Alfabetização, importa considerar que o PNAIC - remodelado pelo MEC, por meio da Portaria $n^{\circ}$ 826, de 7 de julho de 2017 - apresenta como um de seus objetivos a garantia de que todos os alunos estejam alfabetizados até o $3^{\circ}$ ano do ensino fundamental, ou seja, mais uma contradição, o que demonstra mais uma vez a falta de um critério lógico do MEC para seguir o rumo definido no PNE.

Essa falta de critério na elaboração de políticas públicas voltadas à alfabetização é tamanha que o PNAIC e o Mais Alfabetização, apesar das contradições evidenciadas, farão parte, ambas, da Política Nacional de Alfabetização: “Art. $9^{\circ}$ O Programa Mais Alfabetização, bem como o Pacto Nacional pela Alfabetização na Idade Certa - PNAIC, regulamento no âmbito da Portaria MEC no 826, de 7 de julho de 2017, integrarão a Política Nacional de Alfabetização.” (BRASIL, 2018b, p. 55).

Portanto, não seria demasiado inferir que o Mais Alfabetização se trata de uma ação meramente política, em ano de eleição, visando trazer holofotes para uma das práticas governistas. Pode-se validar essa inferência, a partir da leitura do excerto transcrito do Termo de Compromisso (entre governos) da Portaria MEC $\mathrm{n}^{\circ}$ 142/2018 (Programa Mais Alfabetização), com viés explicitamente marqueteiro.

Este Governo [estadual, distrital ou municipal] se compromete a estabelecer a alfabetização como prioridade para a gestão e a dar publicidade aos recursos do Programa como procedência do Governo Federal em todas as suas comunicações, comprometendo-se também a divulgar a marca do Ministério da Educação e do Governo Federal. (BRASIL, 2018b, p. 55, grifo nosso).

${ }^{8}$ Estratégia é o termo utilizado pelo MEC para designar o Programa Mais Alfabetização. 
Verifica-se que essa política pública não leva em consideração o que prevê o PNE (que os alunos devem estar alfabetizados ao final do $3^{\circ}$ ano do EF), apesar de alegar que o programa surge da utilização os resultados obtidos na ANA.

O Programa Mais Alfabetização surgiu como estratégia do Ministério da Educação diante dos resultados da Avaliação Nacional da Alfabetização ANA, do Sistema de Avaliação da Educação - SAEB, criada com o intuito de avaliar o nível de alfabetização dos estudantes ao final do $3^{\circ}$ ano do ensino fundamental, apontou uma quantidade significativa de crianças nos níveis insuficientes de alfabetização (leitura, escrita e matemática). (BRASIL, 2018c, p. 3-4).

A quantidade significativa de crianças nos níveis insuficientes de alfabetização (considerando leitura e escrita) constatada na ANA, comprova a falta de efetividade das políticas, o que ocorre por conta, na maioria das vezes, de falhas na implementação e/ou na execução.

Em relação à leitura (Quadro 2), os índices obtidos são alarmantes, porque mais da metade das crianças ao final do $3^{\circ}$ ano do ensino fundamental ainda não aprenderam a ler.

Quadro 2: Interpretação pedagógica da escala de leitura da ANA

\begin{tabular}{|c|l|c|}
\hline Nível & \multicolumn{1}{|c|}{ Descrição } & $\begin{array}{c}\text { ANA } \\
\text { \% de alunos }\end{array}$ \\
\hline $\begin{array}{c}\text { Nível 1 } \\
\text { que 425 pontos }\end{array}$ & $\begin{array}{l}\text { Neste nível, os estudantes provavelmente são capazes de: } \\
\text { - Ler palavras com estrutura silábica canônica, não canônica, ainda que } \\
\text { alternem sílabas canônicas e não canônicas. }\end{array}$ & $22 \%$ \\
\hline \multirow{2}{*}{ Nível 2} & $\begin{array}{l}\text { Além das habilidades descritas no nível anterior, os estudantes provavelmente } \\
\text { são capazes de: } \\
\text { - Localizar informações explícitas em textos curtos, como piada, parlenda, } \\
\text { poema, quadrinho, fragmentos de narrativas e de curiosidade científica, e em } \\
\text { textos de maior extensão, quando a informação está localizada na primeira linha } \\
\text { do texto. }\end{array}$ & \\
- Rue 525 pontos & $\begin{array}{l}\text { infográfico, receita, bilhete, anúncio, com ou sem apoio de imagem. } \\
\text { - Identificar assunto em textos como campanha publicitária, curiosidade } \\
\text { científica ou histórica, fragmento de reportagem e poema cujo assunto está no } \\
\text { título ou na primeira linha. } \\
\text { - Inferir relação de causa e consequência em tirinha. }\end{array}$ & $33 \%$ \\
\hline Nível 3 & $\begin{array}{l}\text { Além das habilidades descritas nos níveis anteriores, os estudantes } \\
\text { provavelmente são capazes de: } \\
\text { - Localizar informação explícita em textos de maior extensão como fragmento } \\
\text { de literatura infantil, curiosidade científica, sinopse, lenda, cantiga folclórica e } \\
\text { poema, quando a informação está localizada no meio ou ao final do texto. } \\
\text { - Identificar o referente de um pronome pessoal do caso reto em textos como } \\
\text { tirinha e poema narrativo. } \\
\text { - Inferir relação de causa e consequência em textos verbais como piada, fábula, } \\
\text { fragmentos de textos de literatura infantil e texto de curiosidade científica, com } \\
\text { base na progressão textual; informação em textos como história em quadrinhos, } \\
\text { tirinha, piada, poema e cordel; assunto em textos de divulgação científica e }\end{array}$ & $32 \%$ \\
\hline
\end{tabular}




\begin{tabular}{|c|c|c|}
\hline & $\begin{array}{l}\text { fragmento de literatura infantil; e sentido de expressão de uso cotidiano em } \\
\text { textos como poema narrativo, fragmentos de literatura infantil, de curiosidade } \\
\text { científica e tirinha. }\end{array}$ & \\
\hline $\begin{array}{c}\text { Nível } 4 \\
<\text { ou }=\mathrm{a} 625 \text { pontos }\end{array}$ & $\begin{array}{l}\text { Além das habilidades descritas nos níveis anteriores, os estudantes } \\
\text { provavelmente são capazes de: } \\
\text { - Identificar o referente de: pronome possessivo em poema e cantiga; advérbio } \\
\text { de lugar em reportagem; pronome demonstrativo em fragmento de texto de } \\
\text { divulgação científica para o público infantil; pronome indefinido em fragmento } \\
\text { de narrativa infantil; e pronome pessoal oblíquo em fragmento de narrativa } \\
\text { infantil. } \\
\text { - Identificar relação de tempo entre ações em fábula e os interlocutores de um } \\
\text { diálogo em uma entrevista ficcional. } \\
\text { - Inferir sentido de expressão não usual em fragmento de texto de narrativa } \\
\text { infantil. }\end{array}$ & $13 \%$ \\
\hline \multicolumn{2}{|r|}{ Total } & $100 \%$ \\
\hline
\end{tabular}

Fonte: BRASIL (2018a)

Os dados mostram que $55 \%$ dos alunos do $3^{\circ}$ ano do EF estão nos níveis 1 (22\%) e 2 (33\%), sendo considerados inaptos em leitura. Esses estudantes são incapazes de identificar a finalidade de um texto e não conseguem localizar uma informação explícita que não esteja na primeira linha do texto. Ou seja, mais da metade dos alunos que realizaram a ANA não sabe ler com fluência.

Em relação à escrita, os resultados da ANA (Quadro 3) demonstram, também, índices preocupantes o que revela a falta de efetividade do ensino-aprendizagem disponibilizados às crianças brasileiras no que se refere à alfabetização.

Quadro 3: Interpretação pedagógica da escala de escrita da ANA

\begin{tabular}{|c|c|c|}
\hline Nível & Descrição & \begin{tabular}{|c|} 
ANA \\
$\%$ de alunos
\end{tabular} \\
\hline $\begin{array}{c}\text { Nível } 1 \\
>\text { que } 350 \text { pontos }\end{array}$ & $\begin{array}{l}\text { Em relação à escrita de palavras, os estudantes que se encontram neste nível } \\
\text { provavelmente não escrevem as palavras ou estabelecem algumas } \\
\text { correspondências entre as letras grafadas e a pauta sonora, porém ainda não } \\
\text { escrevem palavras alfabeticamente. Em relação à produção de textos, os } \\
\text { estudantes provavelmente não escrevem o texto ou produzem textos } \\
\text { ilegíveis. }\end{array}$ & $14 \%$ \\
\hline $\begin{array}{c}\text { Nível } 2 \\
<\text { ou }=\text { a } 350 \text { e } \\
>\text { que } 450 \text { pontos }\end{array}$ & $\begin{array}{l}\text { Em relação à escrita de palavras, os estudantes que se encontram neste nível } \\
\text { provavelmente escrevem alfabeticamente palavras com trocas ou omissão de } \\
\text { letras, alterações na ordem das letras e outros desvios ortográficos. Em relação } \\
\text { à produção de textos, os estudantes provavelmente não escrevem ou } \\
\text { produzem textos ilegíveis. }\end{array}$ & $17 \%$ \\
\hline $\begin{array}{c}\text { Nível } 3 \\
<\text { ou }=\text { a } 450 \text { e } \\
>\text { que } 500 \text { pontos }\end{array}$ & $\begin{array}{l}\text { Em relação à escrita de palavras, os estudantes que se encontram neste nível } \\
\text { provavelmente escrevem ortograficamente palavras com estrutura silábica } \\
\text { consoante-vogal, apresentando alguns desvios ortográficos em palavras com } \\
\text { estruturas silábicas mais complexas. Em relação à produção de textos, } \\
\text { provavelmente escrevem de forma incipiente ou inadequada ao que foi } \\
\text { proposto, sem as partes da história a ser contada, ou produzem fragmentos sem } \\
\text { conectivos e/ou recursos de substituição lexical e/ou pontuação para estabelecer } \\
\text { articulações entre partes do texto. Apresentam ainda grande quantidade de } \\
\text { desvios ortográficos e de segmentação ao longo do texto. }\end{array}$ & $2 \%$ \\
\hline
\end{tabular}




\begin{tabular}{|c|c|c|}
\hline $\begin{array}{c}\text { Nível } 4 \\
<\text { ou }=\text { a } 500 \text { e } \\
>\text { que } 600 \text { pontos }\end{array}$ & $\begin{array}{l}\text { Em relação à escrita de palavras, os estudantes que se encontram neste nível } \\
\text { provavelmente escrevem ortograficamente palavras com diferentes estruturas } \\
\text { silábicas. Em relação à produção de textos, provavelmente atendem à proposta } \\
\text { de dar continuidade a uma narrativa, embora possam não contemplar todos os } \\
\text { elementos da narrativa e/ou partes da história a ser contada. Articulam as partes } \\
\text { do texto com a utilização de conectivos, recursos de substituição lexical e outros } \\
\text { articuladores, mas ainda cometem desvios que comprometem parcialmente o } \\
\text { sentido da narrativa, inclusive por não utilizar a pontuação ou utilizar os sinais } \\
\text { de modo inadequado. Além disso, o texto pode apresentar poucos desvios de } \\
\text { segmentação e alguns desvios ortográficos que não comprometem a } \\
\text { compreensão. }\end{array}$ & $58 \%$ \\
\hline $\begin{array}{c}\text { Nível } 5 \\
<\mathrm{ou}=\mathrm{a} 600 \text { pontos }\end{array}$ & $\begin{array}{l}\text { Em relação à escrita de palavras, os estudantes que se encontram neste nível } \\
\text { provavelmente escrevem ortograficamente palavras com diferentes estruturas } \\
\text { silábicas. Em relação à produção de textos, provavelmente atendem à proposta } \\
\text { de dar continuidade a uma narrativa, evidenciando uma situação inicial, central } \\
\text { e final, com narrador, espaço, tempo e personagens. Articulam as partes do } \\
\text { texto com conectivos, recursos de substituição lexical e outros articuladores } \\
\text { textuais. Segmentam e escrevem as palavras corretamente, embora o texto } \\
\text { possa apresentar poucos desvios ortográficos e de pontuação que não } \\
\text { comprometem a compreensão. }\end{array}$ & $8 \%$ \\
\hline \multicolumn{2}{|r|}{ Total } & $100 \%$ \\
\hline
\end{tabular}

Fonte: Brasil (2018a, grifos nossos).

Os dados revelam que $33 \%$ dos alunos do $3^{\circ}$ ano do EF estão nos níveis 1 (14\%), 2 (17\%) e 3 (2\%), sendo considerados inaptos em escrita. Esses estudantes, portanto, não sabem escrever com correção, tampouco são capazes de produzir textos legíveis.

Esses índices catastróficos servem de "adubo para fertilizar politicagem”, na medida em viabiliza ideias que surgem como salvadoras da educação brasileira. Nesse contexto, o governo brasileiro, via MEC, criou a Política Nacional de Alfabetização (BRASIL, 2017b), pretendendo disponibilizar um professor assistente para cada uma das 200.000 turmas de $1^{\circ}$ e $2^{\circ}$ ano do EF. Diante dessa proposta, questiona-se: Como contratar 200.000 assistentes de alfabetização com competência para desempenhar a função? E mais: Como vai se dar essa contratação, se o Mais Alfabetização deixa a cargo dos estados, distrito federal e municípios a voluntariedade para participar do programa, mediante a contrapartida marqueteira? Essas questões expõem a fragilidade da proposta, reiterando práticas ineficazes, fantasiosas, fadadas ao insucesso.

Mas, diante desse quadro alarmante, o que fazer para melhorar esses índices? Ou melhor, o que fazer para, de fato, alfabetizar as crianças brasileiras? Alfabetizar as crianças efetivamente implica partir rumo ao objetivo por um caminho estabelecido por política(s) pública(s) de Estado bem desenhada(s), implementada(s) e executada(s) a curto, médio e longo prazo independentemente do grupo político que esteja no poder, exercendo a gestão educacional seja em âmbito nacional, estadual, distrital ou municipal. Nisso, inclui-se definir quando e como as crianças devem ser alfabetizadas. 


\section{Ordenamento jurídico: segurança jurídica para gestores escolares e professores}

Diante dessa desconexão provocada pela $\mathrm{BNCC}$ em relação ao que estabelece o PNE, os gestores educacionais (nos municípios) e, principalmente, os gestores escolares (equipes diretivas) e os professores podem se sentir diante de um dilema: E agora? Seguir, cegamente, o que prescreve a BNCC ou trabalhar para atingir a meta 5 do PNE no prazo determinado $\left(3^{\circ}\right.$ ano do $\mathrm{EF})$ ?

Verifica-se que há um conflito entre duas normas jurídicas que são hierarquicamente diferentes, pois o PNE trata-se de uma Lei, enquanto a BNCC é uma Resolução. A Pirâmide de Kelsen ${ }^{9}$ (Quadro 4) pode ajudar a solucionar esse dilema, ao apresentar um escalonamento das normas jurídicas.

Quadro 4: Hierarquia das normas jurídicas

\begin{tabular}{|c|c|}
\hline $\begin{array}{c}\text { Hierarquia de normas jurídicas relacionadas com } \\
\text { a alfabetização no Brasil }\end{array}$ & $\begin{array}{c}\text { Hierarquia de normas jurídicas, tomando como } \\
\text { parâmetro a Pirâmide de Kelsen (2011). }\end{array}$ \\
\hline $\begin{array}{c}\text { Constituição da República Federativa do Brasil } \\
\text { Promulgada em 5 de outubro de 1988. }\end{array}$ & Constituição \\
\hline- & Leis e Emendas constitucionais \\
\hline- & Leis delegadas \\
\hline $\begin{array}{c}\text { Plano Nacional de Educação (2014-2024) } \\
\text { Lei no 13.005, de 25/06/2014. }\end{array}$ & Leis ordinárias \\
\hline- & Decreto-Lei \\
\hline- & Regulamentos \\
\hline- & Tratados, Acordos, Atos, Convenções Internacionais \\
\hline- & Analogias \\
\hline- & Princípios Gerais do Direito \\
\hline- & Costumes \\
\hline- & Doutrinas \\
\hline $\begin{array}{c}\text { - } \\
\text { - }\end{array}$ & Jurisprudências \\
\hline $\begin{array}{l}\text { Base Nacional Comum Curricular } \\
\text { Resolução CNE/CP n } 2 \text { de 22/12/2017 }\end{array}$ & Decretos, Medidas Provisórias, Resoluções \\
\hline $\begin{array}{l}\text { Pacto Nacional para Alfabetização na Idade Certa } \\
\text { Pograma Mais Alfabetização }\end{array}$ & Portarias, Atos Normativos \\
\hline Portaria 142/2018-MEC. & Contratos em geral \\
\hline
\end{tabular}

Fonte: Kelsen (2011) - adaptado pelos autores

A análise da legislação, considerando a Pirâmide de Kelsen (2011), viabiliza o entendimento sobre qual das normas deve ser seguida, a fim de dar segurança jurídica às equipes diretivas das escolas e aos professores, no sentido de não reprovar alunos que, por ventura, não

${ }^{9}$ A Pirâmide de Kelsen é uma abstração que apresenta a ideia de ordenamento jurídico, por meio da hierarquização das normas jurídicas estruturadas. A norma mais importante ocupa o topo da Pirâmide e subordina as demais normas jurídicas de hierarquia inferior. 
tenham atingido, ao término do $2^{\circ}$ do $\mathrm{EF}$, os níveis mínimos de alfabetização exigidos pela BNCC, adotando o que prevê o PNE, ou seja, alunos alfabetizados ao final do $3^{\circ}$ ano de EF.

Assim, pode-se afirmar que a BNCC, no que se refere à alfabetização, não é válida dentro do ordenamento jurídico o qual é abrangido pelo PNE. Nesse contexto, pode-se inferir que há uma tentativa de imposição de uma política pública de governo (a BNCC, quanto à alfabetização) sobre uma política pública de Estado (o PNE, quanto à meta 5).

\section{Considerações finais}

Do exposto, reitera-se a importância da alfabetização para o avanço das sociedades, inclusive validada pela Organização das Nações Unidas - ONU ao incluir o índice de analfabetismo com um dos aspectos a serem considerados para a obtenção do Índice de Desenvolvimento Humano - IDH.

Apesar dessa relevância evidenciada, no Brasil, a alfabetização mantém-se com um dos problemas a serem resolvidos. No entanto, verifica-se a falta de coordenação, ou melhor, o confronto de objetivos entre as políticas públicas voltadas para essa demanda nacional.

Isso se revela ao confrontar o que pretende o PNE (alfabetizar até $3^{\circ}$ ano do EF) e o propõe a BNCC (alfabetizar até o $2^{\circ}$ ano do EF). Em julho de 2017, por meio do PNAIC, temse a pretensão de alfabetizar os alunos até o $3^{\circ}$ ano do EF, mas, em dezembro de 2017, o MEC simplesmente muda de ideia e, por meio da BNCC, passa a pretender a alfabetização até o $2^{\circ}$ ano do EF.

Essa "aceleração no passo" em busca da alfabetização de crianças ainda mais jovens (aos sete anos e não mais aos oito, como prevê o PNE) exige mudanças acentuadas no que diz respeito à organização do processo pedagógico até então desenvolvido. Os professores alfabetizadores podem se sentir em uma encruzilhada: Qual o caminho o seguir: continuar desenvolvendo atividades lúdicas que visam estimular as crianças a se reconhecerem no mundo e aprendendo sobre ele, ou propor o aprendizado de conteúdos, visando à alfabetização mais precoce, ou ainda tentar um mix dos dois o que pode resultar em não atingir nem um objetivo, nem outro?

Logo, infere-se que a antecipação pretendida pela BNCC pode ter resultados devastadores no sentido de altos índices de não alfabetização ao término do $2^{\circ}$ ano do EF. Por outro lado, a antecipação do ensino conteudista pode contribuir para que a meta 5 do PNE seja atingida, afinal poderão ser dois anos de ações pedagógicas voltadas à alfabetização mais um ano que poderá ser utilizado para atender, pelo menos, a metade dos alunos que, a continuar nesse ritmo de 
aprendizagem, ainda não estarão alfabetizados. Talvez seja essa a intenção implícita do MEC. Essa resposta somente será respondida com os índices da ANA, a partir de 2020, isso se essa avaliação continuar sendo realizada no $3^{\circ}$ ano.

Este estudo, também, explicita que há ampla legislação sobre alfabetização, afinal existem planos, diretrizes e bases, pactos e programas, mas apesar disso, há pouca efetividade. Dados da ANA realizada em 2016 corroboram essa constatação, afinal mais da metade das crianças avaliadas não sabem ler e que mais de um terço delas não consegue escrever palavras de maneira alfabética, produzindo textos ilegíveis.

Isso pode ser reflexo, justamente, dessa desconexão que há entre as políticas implementadas, bem como das alterações constantes nas políticas públicas, particularmente as de governo. Essa volatilidade em relação às determinações políticas, contrariedades inadmissíveis em um Estado democrático de direito continuam ocorrendo sem que haja reação da sociedade no sentido de evitar tempo gasto com equívocos que não deveriam ocorrer, deixando de trilhar um rumo definido com a ampla participação de instâncias representativas no âmbito educacional brasileiro e, consequentemente, inibindo e/ou dificultando a realização de trabalhos efetivos que poderiam contribuir para avanços reais na educação.

Sobre esse aspecto, é preciso considerar que internalizar as mudanças, constantemente propostas por meio de diversas políticas, na forma de educação pública oferecida implica tempo de adaptação da população (alunos e professores - menos; pais - mais). As alterações de oito para nove anos de ensino fundamental ${ }^{10}$, bem como da nomenclatura de $1^{\mathrm{a}}$ a $8^{\mathrm{a}}$ série para $1^{\mathrm{o}}$ a $9^{\circ}$ ano, por exemplo, ainda não foram totalmente assimiladas, mesmo passada mais de uma década.

Nesse contexto, entende-se que a alfabetização das crianças passa muito mais pela ação de professores, coadjuvados pelos pais, do que pela instituição de planos, programas e pactos. Essas políticas têm se mostrado ineficazes, na medida em que privilegiam colocar no papel ações imediatistas. As ações de trabalho efetivo nas escolas são o que de melhor pode ocorrer no que se refere à educação e, particularmente, à alfabetização, ou seja, são as ações da comunidade escolar (equipes diretivas, professores, alunos, pais e mães, etc.) que podem mudar o panorama atual da alfabetização no Brasil.

Por fim, infere-se do exposto neste texto que parece mais sensato, razoável e coerente, projetar, elaborar, instituir planos/programas, enfim, políticas públicas que atendam as

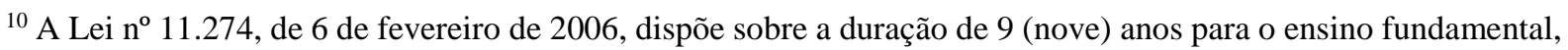
com matrícula obrigatória a partir dos 6 (seis) anos de idade 
estratégias traçadas no PNE, sem “forçar a barra”, isto é, fazer o que já deveria ter sido feito em termos de Educação, por exemplo: aprimorar a estrutura física das escolas e melhorar as condições de trabalho dos professores (planos de carreira, melhor remuneração, jornada de trabalho em apenas um estabelecimento escolar, etc.), dentre outras, do que se aventurar na criação de novos programas, sem sequer realizar um teste-piloto para verificar sua efetividade, como é o caso do Mais Alfabetização.

\section{REFERÊNCIAS}

BRASIL. Constituição 1988. Constituição da República Federativa do Brasil: texto constitucional promulgado em 5 de outubro de 1988, com as alterações determinadas pelas Emendas Constitucionais de Revisão nos 1 a 6/94, pelas Emendas Constitucionais nos 1/92 a 91/2016 e pelo Decreto Legislativo no 186/2008. Brasília: Senado Federal, Coordenação de Edições Técnicas, 2016. 496 p.

BRASIL. Lei n. 9.394, de 20 de dezembro de 1996. Estabelece as diretrizes e bases da educação nacional. Diário Oficial [da] República Federativa do Brasil, Brasília, v. 134, n. 248, p. 1-9, 23 dez. 1996. Seção 1.

BRASIL. Secretaria de Educação Fundamental. Parâmetros curriculares nacionais: língua portuguesa. Brasília: MEC, 1997.

BRASIL. Secretaria de Ensino Fundamental. Programa de desenvolvimento profissional continuado: alfabetização. Módulo alfabetizar com textos. Brasília: A Secretaria, 1999.

BRASIL. Lei n. 10.172, de 9 de janeiro de 2001. Aprova o Plano Nacional de Educação e dá outras providências. Diário Oficial [da] República Federativa do Brasil, Brasília, DF, v. 139, n. 7, p. 1-20, 10 jan. 2001. Seção 1.

BRASIL. Lei n. 11.274, de 6 de fevereiro de 2006. Altera a redação dos arts. 29, 30, 32 e 87 da Lei n. 9.394, de 20 de dezembro de 1996, que estabelece as diretrizes e bases da educação nacional, dispondo sobre a duração de 9 (nove) anos para o ensino fundamental, com matrícula obrigatória a partir dos 6 (seis) anos de idade. Diário Oficial [da] República Federativa do Brasil, Brasília, v. 143, n. 27, p. 1-2, 7 fev. 2006. Seção 1.

BRASIL. Ministério da Educação. Portaria n. 867, de 4 de julho de 2012. Institui o Pacto pela Educação na Idade Certa e as ações do Pacto e define suas diretrizes gerais. Diário Oficial [da] República Federativa do Brasil, Brasília, DF, v. 149, n. 129, p. 22-23, 5 jul. 2012. Seção 1. Brasília, DF, 2012.

BRASIL. Lei n. 13.005, de 25 de junho de 2014. Aprova o Plano Nacional de Educação PNE e dá outras providências. Diário Oficial [da] República Federativa do Brasil, Brasília, DF, v. 151, n. 120-A, edição extra, p. 1-7, 26 jun. 2014. Seção 1.

BRASIL. Ministério da Educação. Base Nacional Comum Curricular. Brasília, DF: MEC, 2017a. Disponível em: http://basenacionalcomum.mec.gov.br/. Acesso em: 25 jul. 2018. 
BRASIL. Ministério da Educação. Política Nacional de Alfabetização. Brasília, DF: MEC, 2017b. Disponível em: http://portal.mec.gov.br/docman/outubro-2017-pdf/75191-maisalfabetizacao-apresentacao-251017-pdf/file. Acesso em: 23 ago. 2018.

BRASIL. Ministério da Educação. Portaria n. 826, de 7 de julho de 2017. Dispõe sobre o Pacto Nacional pela Alfabetização na Idade Certa - PNAIC, suas ações, diretrizes gerais e a ação de formação no âmbito do Programa Novo Mais Educação - PNME. Diário Oficial [da] República Federativa do Brasil, Brasília, DF, v. 154, n. 130, p. 20-23, 10 jul. 2017c. Seção 1.

BRASIL. Instituto Nacional de Estudos e Pesquisas Educacionais Anísio Teixeira. Relatório do $2^{\circ}$ Ciclo de Monitoramento das Metas do Plano Nacional de Educação - 2018.

Brasília, DF: Inep, 2018a.

BRASIL. Ministério da Educação. Portaria n. 142, de 22 de fevereiro de 2018. Institui o Programa Mais Alfabetização. Diário Oficial [da] República Federativa do Brasil, Brasília, DF, v. 155, n. 37, p. 54-55, 23 fev. 2018b. Seção 1.

BRASIL. Ministério da Educação. Programa mais alfabetização: manual operacional do sistema de orientação pedagógica e monitoramento. Brasília: MEC, $2018 \mathrm{c}$.

COSTA, Dania Monteiro Vieira; POTKUL, Renata Strzepa. Produção de textos no Pacto Nacional pela Alfabetização na Idade Certa. Revista Brasileira de Alfabetização, VitóriaES, v. 1, n. 7, p. 234-253, jan./jun. 2018. Disponível em:

http://abalf.org.br/revistaeletronica/index.php/rabalf/article/view/258/197. Acesso em: 18 jul. 2018.

FRANGELLA, Rita de Cássia Prazeres. Entre antíteses e paradoxos: o ciclo de alfabetização nas políticas educacionais. Teoria e Prática da Educação, Maringá-PR, v. 19, n. 3, p. 33-45, set./dez. 2016. Disponível em:

http://periodicos.uem.br/ojs/index.php/TeorPratEduc/article/view/36619/pdf. Acesso em: 4 jun. 2018.

IBGE - Instituto Brasileiro de Geografia e Estatística. Pesquisa Nacional por Amostra de Domicílios Contínua - PNAD Contínua. Educação 2017. IBGE: Rio de Janeiro, 2018. Disponível em: https://biblioteca.ibge.gov.br/visualizacao/livros/liv101576_informativo.pdf. Acesso em: 2 jun. 2018.

INSTITUTO ALFAEBETO. Nota sobre a nova proposta de alfabetização apresentada pelo MEC ao CNE. Versão: 18 de dezembro de 2017. Disponível em: http://arquivos.alfaebeto.org.br/nota-sobre-nova-proposta.pdf. Acesso em 13 ago. 2018.

KELSEN, Hans. Teoria pura do Direito. 7. ed. São Paulo: Revista dos Tribunais, 2011.

MUNIZ, Rita de Fátima; MUNIZ, Sheila Maria. (Re)Pensando a alfabetização na idade certa. Revista Educação \& Linguagem, v. 3, n. 1, p. 24-31, jun. 2016. Disponível em: http://www.fvj.br/revista/wp-content/uploads/2017/05/3_EDUC_20161_v2.pdf. Acesso em 19 jul. 2018. 
OLIVEIRA, João Batista. Alfabetização na BNCC: mais um retrocesso na educação. Revista Veja. Publicado em: 14 dez. 2017. Disponível em: https://veja.abril.com.br/blog/educacaoem-evidencia/alfabetizacao-na-bncc-mais-um-retrocesso-na-educacao/. Acesso em: 15 ago. 2018.

PEROVANO, Nayara Santos; COSTA, Monique Linciano de Azevedo. Políticas monológicas de formação continuada de professores alfabetizadores. Revista Brasileira de Alfabetização, Vitória-ES, v. 1, n. 6, p. 161-175, jul./dez. 2017. Disponível em:

http://abalf.org.br/revistaeletronica/index.php/rabalf/article/view/230/179. Acesso em: 15 jul. 2018.

SNOW, Catherine. Quando os especialistas pararem de gritar uns com os outros, o problema da alfabetização estará resolvido. Nova Escola. 23 mar. 2017. Disponível em:

https://novaescola.org.br/conteudo/4850/alfabetizacao-polemicas-metodo-fonico-idade-certa. Acesso em: 17 jun. 2018.

SOARES, Magda Becker. Letramento e alfabetização: as muitas facetas. Revista Brasileira de Educação, São Paulo, n. 25, p. 5-17, jan./abr. 2004. Disponível em:

http://www.scielo.br/pdf/rbedu/n25/n25a01.pdf. Acesso em: 18 ago. 2018.

WEBER, Max. Economia e sociedade: fundamentos da sociologia compreensiva. Volume 2. Tradução de Regis Barbosa e Karen Elsabe Barbosa; Revisão técnica de Gabriel Cohn.

Brasília, DF: Editora Universidade de Brasília: São Paulo: Imprensa Oficial do Estado de São Paulo, 2004.

\section{Como referenciar este artigo}

FERNANDES, Sergio Brasil; COLVERO, Ronaldo Bernardino. Políticas públicas educacionais contraditórias: a alfabetização em foco. Revista on line de Política e Gestão Educacional, Araraquara, v. 23, n. 2, p. 286-305, maio/ago., 2019. E-ISSN:1519-9029. DOI: 10.22633/rpge.v23i2.11963

Submetido em: 05/12/2018

Revisões requeridas: $26 / 12 / 2018$

Aprovado em: 22/01/2019

Publicado em: 06/03/2019 